\title{
The First Case of Preauricular Fistular Abscess Caused by Peptoniphilus grossensis
}

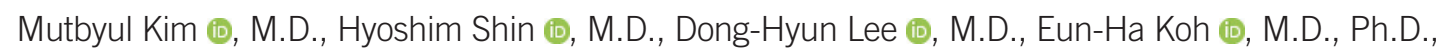
and Jung-Hyun Byun (iD, M.D.

Department of Laboratory Medicine, Gyeongsang National University Hospital, Gyeongsang National University College of Medicine, Jinju, Korea

\section{Dear Editor,}

The genus Peptoniphilus comprises obligatory anaerobic grampositive cocci. The name Peptoniphilus means "affinity to peptones," which are the major energy source of this genus [1]. More than 28 Peptoniphilus species have been isolated from the gut microbiome, and most of them are commensal organisms; Peptoniphilus grossensis was first isolated from human feces [2]. There are no reports on human diseases caused by $P$. grossensis.

A preauricular fistula or sinus is a common congenital abnormality, with a prevalence of approximately $2 \%$ in the Korean population and $0.1 \%-10 \%$ in several other countries [3]. In some cases, it can get infected. We report the first case of a preauricular fistular abscess caused by $P$. grossensis in a human. This study was approved by The Institutional Review Board of Gyeongsang National University Hospital, Jinju, Korea approved the study (approval number 202108013) and waived the need for informed consent.

A 23-year-old woman was admitted for preauricular pain, swelling, and a febrile sensation that started 10 days earlier. Two years prior, she had suffered an Actinomyces odontolyticus-infected preauricular fistula. The remainder of her history was unremarkable. She was suspected of suffering recurrent preauric- ular fistula infections. She had an elevated $\mathrm{C}$-reactive protein level ( $21.5 \mathrm{mg} / \mathrm{L}$; reference range $<5 \mathrm{mg} / \mathrm{L}$ ) and erythrocyte sedimentation rate $(57 \mathrm{~mm} / \mathrm{hr} ; \leq 20 \mathrm{mg} / \mathrm{L})$. Two closed pus specimens were obtained through incision and drainage. Microscopic examination using Gram's stain revealed monomorphic gram-positive cocci, numerous white blood cells (WBCs), and 1-5 epithelial cells per high-power field (Fig. 1). Three days later, anaerobic gram-positive cocci were isolated from a thioglycollate broth culture. They were subcultured on Brucella agar plates and incubated in an anaerobic chamber. The bacteria grew slowly, and a pinpoint colony formed after two days (Fig. 1). The colony was non-hemolytic, grayish, and circular. The bacteria were small gram-positive cocci.

The bacteria could not be identified by matrix-associated laser desorption ionization-time of flight mass spectrometry (bioMérieux, Marcy l'Étoile, France). Biochemical testing using the VITEK 2 system (bioMérieux) identified the bacteria as $P$. asaccharolyticus, with a 95\% probability. 16S rRNA sequencing was performed to identify the bacterial species. According to the EzTaxon database (v2.1; http://www.ezbiocloud.net), the bacteria were identical to P. grossensis (100\%), followed by P. senegalensis (99.42\%), P. lacydonensis, and P. rhinitidis (99.14\%). As $16 \mathrm{~S}$ rRNA sequencing did not provide resolution at the species
Received: August 25, 2021

Revision received: November 14, 2021

Accepted: January 17, 2022

Corresponding author: Jung-Hyun Byun, M.D.

Department of Laboratory Medicine, Gyeongsang National University Hospital, Gyeongsang National University College of Medicine,

79 Gangnam-ro, Jinju 52727, Korea

Tel: +82-55-750-8423, Fax: +82-55-762-2696

E-mail: microbyun@gmail.com, jhbyun@gnuh.co.kr

\section{(c) $(1) \Theta$}

(C) Korean Society for Laboratory Medicine

This is an Open Access article distributed under the terms of the Creative Commons Attribution Non-Commercial License (https://creativecommons.org/licenses/by-nc/4.0) which permits unrestricted non-commercial use, distribution, and reproduction in any medium, provided the original work is properly cited. 

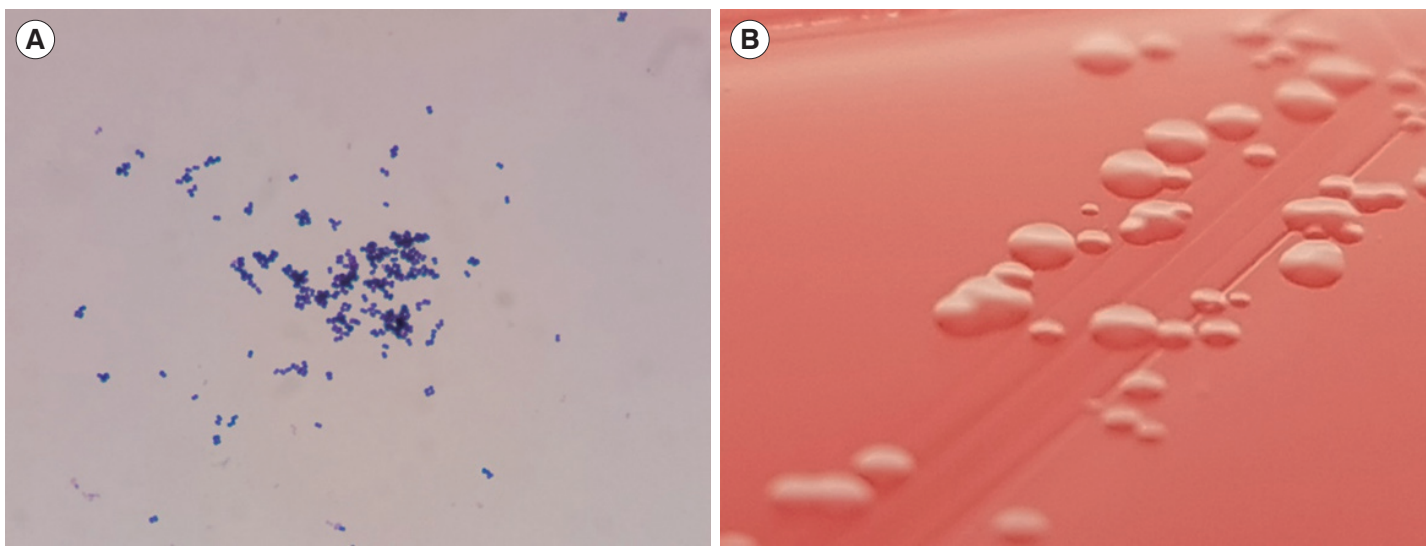

Fig. 1. Microscopic image and colony morphology of Peptoniphilus grossensis. (A) Gram-positive cocci (Gram stain, $\times 1,000)$. (B) Pinpoint and grayish colonies $(\times 100)$ on a Brucella agar plate after 48 hours incubation.

level, whole-genome sequencing using the Illumina MiSeq platform (Illumina, San Diego, CA, USA) was performed. The genome size of the pathogen was 2,038,961 bp, and the data were analyzed using the TrueBac ID-Genome system (www.truebacid.com; ChunLab, Seoul, Korea) [4]. Based on the average nucleotide identity, the bacteria were classified under the genus Peptoniphilus. The bacteria were identified as $P$. grossensis (96. $25 \%)$, P. senegalensis (88.60\%), P. lacydonensis (85.74\%), and P. rhinitidis (85.83\%). Beta-lactamase screening was negative.

Intravenous ampicillin/sulbactam was administered for four days after initial incision and drainage. The patient was discharged as no bleeding or purulent discharge from the wound was observed. An oral cefditoren, a third-generation cephalosporin, was prescribed for seven days for preauricular pain at the time of discharge.

Gram-positive anaerobic cocci are mostly commensal and opportunistic pathogens [5]. Infections from these bacteria are often polymicrobial [6]. Therefore, the clinical significance of individual anaerobic cocci is difficult to determine in clinical practice. Herein, monomorphic gram-positive cocci and numerous WBCs were observed on a direct smear of closed pus obtained aseptically. A single species was recovered, indicating that this bacterium caused the infection and highly likely is pathogenic.

Peptoniphilus are fastidious bacteria and identifying them clinically is time-consuming. P. grossensis was isolated but not identified within a clinically significant timeframe. Antibiotic susceptibility testing of anaerobic bacteria is not feasible in most clinical settings, because it requires manual agar dilution or broth microdilution with supplementation of hemin, vitamin $\mathrm{K}$, and laked sheep or horse blood [7]. We identified three antibiotic-resistance genes in the isolate genome: erm (A), which confers resistance to erythromycin, and aph(3')-IIla and ant(6)-la, which confer resistance to aminoglycosides. We did not assess phenotypic antibiotic susceptibility, because the clinical breakpoints for macrolides and aminoglycosides are not provided in the CLSI or European Committee on Antimicrobial Susceptibility Testing guidelines [7, 8]. Anaerobic gram-positive cocci, including Peptoniphilus spp., do not exhibit high-level resistance against other antibiotics [6, 9]. After incision, drainage, and beta-lactam combination drug treatment as empirical therapy, the prognosis of the patient was good.

This report highlights the potential pathogenicity of $P$. grossensis, even in immunocompetent young subjects. Technological advances can help detect and identify more bacteria in human specimens. Further investigation of the pathogenesis and clinical significance of rare bacteria such as $P$. grossensis is needed $[5,10]$.

\section{ACKNOWLEDGEMENTS}

We thank Jaewon Jang, Chang Kun Ha, and Jongbok Lee for technical support.

\section{AUTHOR CONTRIBUTIONS}

Conceptualization: Byun JH. Data curation: Kim M, Shin H, Lee $\mathrm{DH}$, Koh EH. Writing-review and editing: Byun JH, Kim M. Final approval of the manuscript: all authors.

\section{CONFLICTS OF INTEREST}

The authors have no conflicts of interest to declare. 


\section{RESEARCH FUNDING}

This work was supported by the National Research Foundation of Korea grant funded by the Korea government MSIT (No. 2020 R1F1A1066895), (No. 2021M3E5E3080382) and by the Korean Centers for Disease Control and Prevention (No. 2019ER5501-00).

\section{ORCID}

Mutbyul Kim

https://orcid.org/0000-0001-5537-9781

Hyoshim Shin https://orcid.org/0000-0001-9737-2393

Dong-Hyun Lee https://orcid.org/0000-0001-5880-4528

Eun-Ha Koh https://orcid.org/0000-0002-4625-1396

Jung-Hyun Byun

\section{REFERENCES}

1. Ezaki T, Kawamura Y, Li N, Li ZY, Zhao L, Shu S. Proposal of the genera Anaerococcus gen. nov., Peptoniphilus gen. nov. and Gallicola gen. nov. for members of the genus Peptostreptococcus. Int J Syst Evol Microbiol 2001;51:1521-8

2. Mishra AK, Hugon P, Robert C, Raoult D, Fournier PE. Non contiguous-

finished genome sequence and description of Peptoniphilus grossensis sp. nov. Stand Genomic Sci 2012;7:320-30.

3. Lee KY, Woo SY, Kim SW, Yang JE, Cho YS. The prevalence of preauricular sinus and associated factors in a nationwide population-based survey of South Korea. Otol Neurotol 2014;35:1835-8.

4. Ha SM, Kim CK, Roh J, Byun JH, Yang SJ, Choi SB, et al. Application of the whole genome-based bacterial identification system, TrueBac ID, using clinical isolates that were not Identified with three matrix-assisted laser desorption/ionization time-of-flight mass spectrometry (MALDI-TOF MS) systems. Ann Lab Med 2019;39:530-6.

5. Murphy EC and Frick IM. Gram-positive anaerobic cocci-commensals and opportunistic pathogens. FEMS Microbiol Rev 2013;37:520-53.

6. Brown K, Church D, Lynch T, Gregson D. Bloodstream infections due to Peptoniphilus spp.: report of 15 cases. Clin Microbiol Infect 2014;20: 0857-60.

7. CLSI. Performance standards for antimicrobial susceptibility testing. 31st ed. CLSI M100. Wayne, PA: Clinical Laboratory Standards Institute, 2021.

8. European Committee on Antimicrobial Susceptibility Testing. Breakpoint tables for interpretation of MICs and zone diameters. version 11.0, 2021. http://www.eucast.org (Updated on 1 Jan 2021).

9. Byun JH, Kim M, Lee Y, Lee K, Chong Y. Antimicrobial susceptibility patterns of anaerobic bacterial clinical isolates from 2014 to 2016, including recently named or renamed species. Ann Lab Med 2019;39: 190-9.

10. Han A, Zenilman JM, Melendez JH, Shirtliff ME, Agostinho A, James G, et al. The importance of a multifaceted approach to characterizing the microbial flora of chronic wounds. Wound Rep Reg 2011;19:532-41. 